\title{
Overexpression of the $C B F 2$ transcriptional Activator Enhances Oxidative Stress Tolerance in Arabidopsis Plants
}

\author{
Michal Sharabi-Schwager \\ Department of Postharvest Science of Fresh Produce, ARO, the Volcani Center, \\ P.O. Box 6, Bet Dagan 50250, Israel \\ Tel.: 972-3-9683617 E-mail: rporat@volcani.agri.gov.il \\ Ron Porat (Corresponding author) \\ Department of Postharvest Science of Fresh Produce, ARO, the Volcani Center, \\ P.O. Box 6, Bet Dagan 50250, Israel \\ Tel.: 972-3-9683617 E-mail: rporat@volcani.agri.gov.il
}

Alon Samach

The Robert H. Smith Institute of Plant Sciences and Genetics in Agriculture

Faculty of Agricultural, Food and Environmental Quality Sciences, the Hebrew University of Jerusalem, P.O. Box 12, Rehovot 76100, Israel.

Received: January 21, 2011 Accepted: February 09, 2011 doi:10.5539/ijb.v3n2p94

\begin{abstract}
The C-repeat/dehydration-responsive-element binding factor genes (CBF1-3) are transcriptional activators involved in governing plant responses to low temperatures; their overexpression enhances plant frost tolerance. We found that overexpression of $C B F 2$ in Arabidopsis enhanced oxidative stress tolerance as compared with wild-type plants, an effect that was manifested in: increased seed germination rates on Petri dishes containing $\mathrm{H}_{2} \mathrm{O}_{2}$; delayed leaf senescence following incubation with $\mathrm{H}_{2} \mathrm{O}_{2}$; and delayed wilting and senescence after spraying whole plants with paraquat, a generator of superoxide radicals. Transcript profiling analysis using the Affymetrix ATH1 genome array revealed that overexpression of $C B F 2$ did not affect expression of reactive oxygen-scavenging genes but rather, remarkably enhanced expression of oxidative-stress-responsive transcription factor genes. Overall, the present findings suggest that overexpression of $C B F 2$ in Arabidopsis enhances oxidative stress tolerance, most likely via activation of a network interaction among stress-related transcription-factor genes.
\end{abstract}

Keywords: Arabidopsis, CBF2, Oxidative stress, Stress tolerance, ROS

\section{Introduction}

Aerobic organisms utilize molecular oxygen as a terminal oxidant during respiration, and thus consistently generate reactive oxygen species (ROS) as a normal by-product of aerobic respiration (Finkel \& Holbrook, 2000; Martin et al., 1996). ROS include singlet oxygen $\left({ }^{1} \mathrm{O}_{2}\right)$, superoxide radical $\left(\mathrm{O}_{2}^{-}\right)$, hydroperoxyl radical $\left(\mathrm{HO}_{2}^{-}{ }^{-}\right)$, hydrogen peroxide $\left(\mathrm{H}_{2} \mathrm{O}_{2}\right)$, and hydroxyl radical $(\cdot \mathrm{OH})$ - all of which are extremely reactive and capable of oxidizing biological molecules such as DNA, proteins, or lipids (Alscher et al., 1997; Schopfer et al., 2001). In addition to generating ROS in mitochondria during oxidative phosphorylation, plants also produce large amounts of ROS in the chloroplasts during photosynthesis and $\mathrm{CO}_{2}$ fixation (Arora et al., 2002; Mittler et al., 2004; Munne-Bosch \& Alegre, 2002). Furthermore, because plants are immobile and fixed in the soil they are constantly exposed to environmental stresses such as unfavorable temperatures (heating, chilling, and freezing), drought, salinity, flooding, pathogen attack, etc. Exposures to such stresses result in massive generation of ROS that interfere with the delicate balance of cellular redox homeostasis (Bolwell et al., 2002; J. Dat et al., 2000; Foyer \& Noctor, 2005). Overall, their status as photosynthesizing organisms and their constant exposure to stresses make plants especially vulnerable to oxidative stresses. Because of the vital importance to control intercellular ROS levels, all aerobic organisms, including plants, developed enzymatic systems to detoxify 
excessive accumulation of ROS, mainly ROS scavenging enzymes such as catalase and superoxide dismutase (Mittler et al., 2004). In addition, many plant transcription factor genes are also regulated by ROS accumulation (Gadjev et al., 2006).

Many plants, including Arabidopsis, increase their frost tolerance in response to low nonfreezing temperatures; a phenomenon known as "cold acclimation" (M. F. Thomashow, 1999). Transcript profiling experiments revealed that multiple regulatory pathways are activated during cold acclimation, and that one such important pathway involves the c-repeat binding factor (CBF) regulon (M. F. Thomashow, 1999; M.F. Thomashow, 2001). The $C B F$ genes are members of a small family of three AP2 domain transcriptional activators, comprising $C B F 1$, $C B F 2$ and $C B F 3$ (Gilmour et al., 2004; Shinwari et al., 1998). Ectopic expression of $C B F 1$ in Arabidopsis induced expression of cold-regulated (COR) genes and significantly enhanced freezing tolerance even without cold acclimation(Gilmour et al., 2004; Jaglo-Ottosen et al., 1998). In addition to frost tolerance, overexpression of $C B F$ genes also induced plant tolerance towards other environmental stresses, such as drought and salinity (Kasuga et al., 1999; Shinozaki \& Yamaguchi-Shinozaki, 2000). Furthermore, it was reported that ectopic expression of $C B F 1$ also induced tolerance to water deficit, chilling, and salt stress in tomato plants (Hsieh et al., 2002a; Lee et al., 2003). Moreover, Hsieh et al. (2002b) suggested that overexpression of CBF1 increased chilling tolerance in tomato by enhancing CATALASE1 gene expression and enzyme activity, and oxidative stress tolerance (Hsieh et al., 2002b). In addition to its effects on induction of plant stress tolerance, we recently reported that overexpression of $C B F 2$ in Arabidopsis also considerably delayed leaf senescence and extended the life span of the plants by approximately 2 weeks as compared with wild-type plants (Sharabi-Schwager et al., 2010). In this study, we show that overexpression of $C B F 2$ enhanced oxidative stress tolerance in Arabidopsis, as manifested in: increased seed germination rates on Petri dishes containing $\mathrm{H}_{2} \mathrm{O}_{2}$; delayed leaf senescence following incubation with $\mathrm{H}_{2} \mathrm{O}_{2}$; and delayed wilting and senescence following spraying of whole plants with paraquat, a generator of superoxide radicals. Also, during growth and development the $C B F 2$-overexpressing plants accumulated much lower levels of $\mathrm{H}_{2} \mathrm{O}_{2}$ and $\mathrm{O}_{2}{ }^{-}$radicals than wild-type plants. Moreover, transcriptome analysis with the Affymetrix ATH1 genome array revealed that overexpression of $C B F 2$ may have enhanced oxidative stress tolerance via activation of a network of oxidative-stress-responsive transcription factor genes.

\section{Materials and Methods}

\subsection{Plant Material and Growth Conditions}

Seeds of Arabidopsis thaliana (L.) Heynh. ecotype Wassilewskija (WS-2) and of transgenic plants overexpressing the $C B F 2$ gene in a WS-2 background were obtained from Prof. M. Thomashow of Michigan State University, MI, USA (Gilmour et al., 2004). Before sowing, seeds were sterilized in $5 \%$ bleach and immersed in water at $4^{\circ} \mathrm{C}$ for $48 \mathrm{~h}$ to ensure uniform germination. The plants were grown in $7 \times 7 \times 8 \mathrm{~cm}$ plastic pots filled with a commercial growing-soil mix, at a constant temperature of $22^{\circ} \mathrm{C}$, and illuminated by cool-white fluorescent lamps at approximately $100 \mu \mathrm{mol} \mathrm{m}{ }^{-2} \mathrm{~s}^{-1}$, with a photoperiod of $16 \mathrm{~h}$. Plants were grown at a density of four plants per pot. In some experiments, seeds were grown on Petri dishes containing $0.8 \%$ agar and $0.5 \times$ Murashige and Skoog (MS) medium including Gamborg B5 vitamins (Duchefa Biochemie, Haarlem, the Netherlands) at $\mathrm{pH}$ 5.7, as described (Weigal \& Glazebrook, 2002).

\subsection{Chlorophyll Content}

Chlorophyll content was measured in 5-mm-diameter leaf disc samples. Chlorophyll was extracted from two leaf discs placed in a microtube containing $1 \mathrm{~mL}$ of $80 \%$ acetone. The discs were homogenized with a fitted pestle and incubated overnight at $4{ }^{\circ} \mathrm{C}$. Chlorophyll content in the acetone extracts was measured spectrometrically according to Porra et al. (Porra et al., 1989). Each measurement included four replications.

\subsection{Electrolyte Leakage}

Electrolyte leakage was measured by placing entire rosettes in scintillation vials containing $10 \mathrm{~mL}$ of double-distilled water. The first reading was taken after $2 \mathrm{~h}$ of incubation at room temperature with gentle agitation, and afterwards the rosettes were exposed to a high level of microwave radiation for $2 \mathrm{~min}$, to destroy all living cells. The vials were then cooled to room temperature, and second readings were taken. Electrolyte leakage data are presented as percentages of the total amount of electrolytes present in the tissue.

\subsection{Exposure to Oxidative Stress}

Oxidative stress tolerance of wild-type and $C B F 2$-overexpressing plants was evaluated by three different means. First, we examined seed germination rates following sowing on MS medium containing various concentrations $(0-10 \mathrm{mM})$ of $\mathrm{H}_{2} \mathrm{O}_{2}$ in Petri dishes. The seed germination rate was determined as the percentage of seeds that survived with each concentration of $\mathrm{H}_{2} \mathrm{O}_{2}$ after 7 days at $22^{\circ} \mathrm{C}$. Second, we evaluated the degree of yellowing of 
detached leaves following incubation in $0-10 \mathrm{mM} \mathrm{H}_{2} \mathrm{O}_{2}$ solutions: leaves numbers 5 and 6 were detached from 36-day-old plants, and incubated for $72 \mathrm{~h}$ at $22^{\circ} \mathrm{C}$, adaxial side up, in Petri dishes containing $\mathrm{H}_{2} \mathrm{O}_{2}$ at $0-10 \mathrm{mM}$. Third, 36-day-old wild-type and $C B F 2$-overexpressing plants were sprayed with various concentrations (0-30 $\mu \mathrm{M}$ ) of paraquat (Sigma, St Louis, MO, USA), a generator of superoxide radicals. In all these experiments, seeds, detached leaves, and whole plants were kept at $22^{\circ} \mathrm{C}$ under a 16 -h photoperiod of illumination at $\sim 100 \mu \mathrm{mol} \mathrm{m}^{-2}$ $\mathrm{s}^{-1}$.

\subsection{NBT and DAB Staining}

To evaluate $\mathrm{H}_{2} \mathrm{O}_{2}$ and $\mathrm{O}_{2}^{-}$levels in plant tissues we used 3,3'-diaminobenzidine (DAB) (J. F. Dat et al., 2003), and nitroblue tetrazolium (NBT) (Le Deunff et al., 2004) staining procedures, respectively. Briefly, leaves numbers 5 and 6 were detached from wild-type and $C B F 2$-overexpressing plants at various development stages and were vacuum infiltrated for $20 \mathrm{~min}$ in $2.5 \mathrm{mM}$ DAB or $500 \mathrm{mM}$ NBT solutions in citrate buffer $(10 \mathrm{mM}$ citrate, $\mathrm{pH}$ 6.0). Afterwards leaves were washed several times with $80 \%$ ethanol in order to remove the green chlorophyll, and the intensity of DAB or NBT staining was assessed visually by photography. In one experiment, entire rosettes of 36-day-old plants were stained in DAB and NBT solutions.

\subsection{Transcript Profiling Analysis}

Total RNA was isolated from leaves numbers 5 and 6 of 40-day-old wild-type and $C B F 2$-overexpressing plants by phenol/chloroform extraction and precipitation with $\mathrm{LiCl}$, according to standard procedures (Sambrook et al., 1992). For each treatment, we performed three separate RNA extractions, each involving leaves from 5 to 10 different plants. The RNA samples were prepared for hybridization according to the protocols outlined in the Affymetrix GeneChip Expression Analysis Technical Manual, and were hybridized to the Affymetrix Arabidopsis ATH1 Genome Array representing 24,000 genes (Affymetrix, Santa Clara, CA, USA). Hybridizations were performed at the Department of Biological Services in the Weizmann Institute of Science, Rehovot, Israel. Data were analyzed with the Affymetrix Microarray Suite 5.0 (MAS5.0) statistical algorithms. Further advanced data analyses, including background subtraction, normalization and elimination of false positives, were performed with the Partek Genomics Suite (Partek GS) statistical and data visualization program. One-way analysis of variance was used to identify probe sets that exhibited significant changes in signal levels at $P \leq 0.05$.

\section{Results}

\subsection{Effects of CBF2-Overexpression on Oxidative Stress Tolerance}

We evaluated the effects of $C B F 2$-overexpression on oxidative stress tolerance by three different means: a) evaluation of seed germination on MS medium containing various concentrations of $0-10 \mathrm{mM} \mathrm{H}_{2} \mathrm{O}_{2} ; b$ ) evaluation of leaf yellowing following incubation in 0-10 $\mathrm{mM} \mathrm{H}_{2} \mathrm{O}_{2}$ solutions; and c) evaluation of whole plant wilting following sprays with $0-30 \mu \mathrm{M}$ paraquat. It can be seen that in all cases, $C B F 2$-overexpressing plants were more tolerant to the imposed oxidative stresses than wild-type plants.

In the seed germination assay, we found that seeds of both wild-type and $C B F 2$-overexpressing plants had high germination rates $(\sim 95 \%)$ on MS agar media containing up to $4 \mathrm{mM} \mathrm{H}_{2} \mathrm{O}_{2}$. However, at higher concentrations of 6 and $8 \mathrm{mM} \mathrm{H}_{2} \mathrm{O}_{2}$ - germination rates were significantly higher in seeds of the transgenic line: 68 and 38\%, respectively, in $C B F 2$-overexpressing plants as compared with just 32 and $13 \%$, respectively, in those of wild-type plants (Figure 1). At the high concentration of $10 \mathrm{mM} \mathrm{H}_{2} \mathrm{O}_{2}$ seed germination was very low (below $14 \%$ ) in both wild-type and CBF2-overexpressing plants (Figure 1).

In the leaf-yellowing assay, we found that leaves of wild-type plants lost chlorophyll following incubation at the lowest concentration of $2.5 \mathrm{mM} \mathrm{H}_{2} \mathrm{O}_{2}$, whereas those of $C B F 2$-overexpressing plants began to loose chlorophyll only after incubation at the higher concentration of $5 \mathrm{mM} \mathrm{H}_{2} \mathrm{O}_{2}$ (Figure 2). Overall, leaves of wild-type plants lost $50 \%$ of their chlorophyll content, as compared with leaves incubated in water alone, after incubation in 5 $\mathrm{mM} \mathrm{H} \mathrm{H}_{2} \mathrm{O}_{2}$, whereas leaves of $C B F 2$-overexpressing plants lost this proportion only after incubation in $\mathrm{H}_{2} \mathrm{O}_{2}$ at the highest concentration of $10 \mathrm{mM}$ (Figure 2B). It can be seen (Figure 2A) that leaves of wild-type plants became transparent and lost almost all of their chlorophyll following incubation at 7.5 and $10 \mathrm{mM} \mathrm{H}_{2} \mathrm{O}_{2}$, whereas leaves of $C B F 2$-overexpressing plants remained green and viable even after incubation at the highest $\mathrm{H}_{2} \mathrm{O}_{2}$ concentration of $10 \mathrm{mM}$.

In the paraquat spray assay, we found that $C B F 2$-overexpressing plants were much more tolerant than wild-type plants to the generated superoxide. It can be seen (Figure 3) that wild-type rosettes suffered from slight necrosis and increased electrolyte leakage rates already after being sprayed with paraquat at the lowest concentration of $10 \mu \mathrm{M}$, whereas the $C B F 2$-overexpressing plants still remained green and healthy. Furthermore, rosettes of 
wild-type plants wilted completely after receiving 20-30 $\mu \mathrm{M}$ paraquat, whereas those of $C B F 2$-overexpressing plants showed necrosis symptoms mainly at the high paraquat concentration of $30 \mu \mathrm{M}$ (Figure 3A). Electrolyte leakage rates in rosettes of wild-type plants increased continuously from $33 \%$ without paraquat to 42,56 , and $76 \%$ following paraquat sprays at 10,20 , and $30 \mu \mathrm{M}$, respectively, whereas electrolyte leakage rates of $C B F 2$-overexpressing plants increased above base level only after exposure to paraquat at the highest concentration of $30 \mu \mathrm{M}$ (Figure 3B).

\subsection{Effects of CBF2-Overexpression on $\mathrm{H}_{2} \mathrm{O}_{2}$ and $\mathrm{O}_{2}{ }^{-}$Contents in Leaves and Rosettes}

We used DAB and NBT staining to evaluate the accumulation of $\mathrm{H}_{2} \mathrm{O}_{2}$ and $\mathrm{O}_{2}{ }^{-}$in leaves of wild-type and $C B F$-overexpressing plants during plant development. Figures 4 and 5, respectively, show that in wild-type plants both $\mathrm{H}_{2} \mathrm{O}_{2}$ and $\mathrm{O}_{2}^{-}$began to accumulate in leaf tissue during initiation of flowering, peaked at mid-flowering, and then declined. In contrast, we did not detect any accumulation of either $\mathrm{H}_{2} \mathrm{O}_{2}$ or $\mathrm{O}_{2}{ }^{-}$in leaves of $C B F 2$-overexpressing plants at any stage of plant development (Figures 4 and 5). Figure 6 shows ROS accumulation in rosettes of wild-type and $C B F 2$-overexpressing plants 36 days after sowing. Once again, it can be seen that rosettes of wild-type plants accumulated high levels of $\mathrm{H}_{2} \mathrm{O}_{2}$ and $\mathrm{O}_{2}^{-}$, whereas those of $C B F 2$-overexpressing plants contained only minor levels of these radicals (Figure 6).

\subsection{Effects of CBF2 Overexpression on Transcript Levels of ROS-Scavenging and Oxidative-Stress-Responsive Transcription Factor Genes}

In order to identify the molecular mechanisms that might be involved in governing the enhanced tolerance of $C B F 2$-overexpressing plants to oxidative stress we analyzed transcript profiles with the Affymetrix ATH1 genome array, and examined the expression patterns of ROS-scavenging and oxidative-stress-responsive transcription factor genes. The list of Arabidopsis ROS-scavenging genes was taken from the review article by Mittler et al. (Mittler et al., 2004). Table 1 shows that none of the Arabidopsis ROS-scavenging genes, including superoxide dismutase $(S O D)$, catalase $(C a t)$, ascorbate peroxidase $(A P X)$, monodehydroascorbate reductase $(M D A R)$, dehydroascorbate reductase (DHAR), glutathione reductase (GR), glutathione peroxidase (GPX), peroxiredoxin $(\operatorname{Prx} R)$ and ferritin were induced or repressed by more than a factor of 2 . Thus, overexpression of $C B F 2$ did not have any direct effect on ROS-scavenging transcript levels.

In addition to the ROS-scavenging system, (Gadjev et al., 2006), on the basis of various ROS-related microarray experiments, defined a group of 32 regulatory Arabidopsis transcription-factor genes whose expression levels were elevated at least fivefold following exposure to various ROS, and Table 2 shows that the transcript levels of 18 out of these 32 oxidative-stress-responsive transcription factor genes were up-regulated at least threefold in $C B F 2$-overexpressing plants. Furthermore, the transcript levels of 10 of these ROS-responsive transcription factor genes were remarkably up-regulated, by more than fivefold, in $C B F 2$-overexpressing plants (Table 2). The ROS-responsive transcription-factor genes induced by $C B F 2$ overexpression belong to various families, including WRKY, NAM, $\mathrm{C}_{2} \mathrm{H}_{2}$ zinc finger, $\mathrm{CCCH}$-type zinc finger AP2, HSF, MYB, ZAT (Table 2).

\section{Discussion}

In the present study, we showed that overexpression of $C B F 2$ further increased oxidative-stress tolerance in Arabidopsis plants, and we demonstrated this by various assays, including evaluation of seed germination, leaf yellowing and whole-plant wilting, in response to various ROS treatments (Figures 1-3). Although not reported before, the finding that overexpression of $C B F 2$ enhanced oxidative-stress tolerance in Arabidopsis is not very surprising; it is known that overexpression of $C B F$ genes enhanced plant tolerance towards various environmental stresses, such as freezing, drought, and salinity (Kasuga et al., 1999; Shinozaki \& Yamaguchi-Shinozaki, 2000). Furthermore, it was previously reported that ectopic expression of $C B F 1$ increased tolerance of chilling and oxidative stress also in tomato plants (Hsieh et al., 2002b).

Since generation of ROS and activation of oxidative processes are known to provide integral components of the senescence syndrome in all aerobic organisms, including plants (Finkel \& Holbrook, 2000; Martin et al., 1996; Prochazkova et al., 2001; Zimmermann \& Zentgraf, 2005), we hypothesize that overexpression of CBF2 might have delayed leaf and whole-plant senescence, at least in part, by increasing oxidative-stress tolerance and/or by reducing ROS accumulation during plant development. Indeed, our present findings clearly demonstrate that overexpression of $\mathrm{CBF} 2$ increased oxidative stress tolerance and remarkably reduced accumulation of $\mathrm{H}_{2} \mathrm{O}_{2}$ and $\mathrm{O}_{2}{ }^{-}$radicals in leaf tissue during development, as compared with that in wild-type plants (Figures 4-6).

Therefore, by analogy with previous studies, which reported that the Arabidopsis delayed-leaf-senescence mutants ore1, ore 3 , and ore 9 , and the long-living mutant gigantea exhibited enhanced tolerance to oxidative stresses (Kurepa et al., 1998; Woo et al., 2004), we hereby suggest that ectopic expression of CBF2 also might 
have delayed senescence and extended plant longevity via enhancement of oxidative stress tolerance. Similar correlations between oxidative stress resistance and extension of life span were reported in various aerobic organisms, ranging from yeasts to mammals (Johnson et al., 1996; Kapahi et al., 1999; Orr \& Sohal, 1994).

Finally, we do not yet know for certain the exact mechanism by which overexpression of $C B F 2$ might have increased oxidative stress tolerance. In tomato, it was reported that overexpression of $C B F 1$ increased chilling tolerance by enhancing CATALASE1 gene expression and enzyme activity (Hsieh et al., 2002b). However, in the current study, we could not detect any induction of genes involved in ROS-scavenging, but rather detected a remarkable up-regulation of transcript levels of 18 out of 32 Arabidopsis ROS-responsive transcription-factor genes (Tables 1-2) (Gadjev et al., 2006). Therefore, we suggest that overexpression of CBF2 might have enhanced oxidative stress tolerance in Arabidopsis via activation of a network of oxidative-stress-responsive transcription-factor genes.

\section{Acknowledgements}

We thank Prof. Michael F. Thomashow and Dr. Sarah J. Gilmour, of Michigan State University, MI, USA, for providing the seeds of CBF2-overexpressing plants. This manuscript is contribution no. 598/10 from the Agricultural Research Organization, the Volcani Center, Bet Dagan 50250, Israel.

\section{References}

Alscher, R. G., Donahue, J. L., \& Cramer, C. L. (1997). Reactive oxygen species and antioxidants: Relationships in green cells. Physiologia Plantarum, 100(2), 224.

Arora, A., Sairam, R. K., \& Srivastava, G. C. (2002). Oxidative stress and antioxidative system in plants. Current Science, 82, 1227-1238.

Bolwell, G. P., Bindschedler, L. V., Blee, K. A., Butt, V. S., Davies, D. R., Gardner, S. L., et al. (2002). The apoplastic oxidative burst in response to biotic stress in plants: A threex€ component system. Journal of Experimental Botany, 53(372), 1367-1376.

Dat, J., Vandenabeele, S., Vranová, E., Van Montagu, M., Inzé, D., \& Van Breusegem, F. (2000). Dual action of the active oxygen species during plant stress responses. Biomedical and Life Sciences, 57(5), 779-795.

Dat, J. F., Pellinen, R., Beeckman, T., Van de Cotte, B., Langebartels, C., Kangasjarvi, J., et al. (2003). Changes in hydrogen peroxide homeostasis trigger an active cell death process in tobacco. Plant Journal, 33(4), 621-632.

Finkel, T., \& Holbrook, N. J. (2000). Oxidants, oxidative stress and the biology of ageing. Nature, 408(6809), 239-247.

Foyer, C. H., \& Noctor, G. (2005). Redox homeostasis and antioxidant signaling: A metabolic interface between stress perception and physiological responses. Plant Cell, 17(7), 1866-1875.

Gadjev, I., Vanderauwera, S., Gechev, T. S., Laloi, C., Minkov, I. N., Shulaev, V., et al. (2006). Transcriptomic footprints disclose specificity of reactive oxygen species signaling in arabidopsis. Plant Physiol., 141(2), 436-445.

Gilmour, S. J., Fowler, S. G., \& Thomashow, M. F. (2004). Arabidopsis transcriptional activators cbf1, cbf2, and cbf3 have matching functional activities. Plant Molecular Biology, 54(5), 767-781.

Hsieh, T.-H., Lee, J.-t., Charng, Y.-y., \& Chan, M.-T. (2002a). Tomato plants ectopically expressing arabidopsis cbf1 show enhanced resistance to water deficit stress. Plant Physiol., 130(2), 618-626.

Hsieh, T.-H., Lee, J.-T., Yang, P.-T., Chiu, L.-H., Charng, Y.-y., Wang, Y.-C., et al. (2002b). Heterology expression of the arabidopsis c-repeat/dehydration response element binding factor 1 gene confers elevated tolerance to chilling and oxidative stresses in transgenic tomato. Plant Physiol., 129(3), 1086-1094.

Jaglo-Ottosen, K. R., Gilmour, S. J., Zarka, D. G., Schabenberger, O., \& Thomashow, M. F. (1998). Arabidopsis cbf1 overexpression induces cor genes and enhances freezing tolerance. Science, 280(5360), 104-106.

Johnson, T. E., Lithgow, G. J., \& Murakami, S. (1996). Hypothesis: Interventions that increase the response to stress offer the potential for effective life prolongation and increased health. Journals Of Gerontology, 51(6), B392-B395.

Kapahi, P., Boulton, M. E., \& Kirkwood, T. B. L. (1999). Positive correlation between mammalian life span and cellular resistance to stress. Free Radical Biology And Medicine, 26(5-6), 495-500.

Kasuga, M., Liu, Q., Miura, S., Yamaguchi-Shinozaki, K., \& Shinozaki, K. (1999). Improving plant drought, salt, and freezing tolerance by gene transfer of a single stress-inducible transcription factor. Nat Biotech, 17(3), 287. 
Kurepa, J., Smalle, J., Van Montagu, M., \& Inze, D. (1998). Oxidative stress tolerance and longevity in arabidopsis: The late-flowering mutant gigantea is tolerant to paraquat. Plant Journal, 14, 759-764.

Le Deunff, E., Davoine, C., Le Dantec, C., Billard, J.-P., \& Huault, C. (2004). Oxidative burst and expression of germin/oxo genes during wounding of ryegrass leaf blades: Comparison with senescence of leaf sheaths. The Plant Journal, 38(3), 421.

Lee, J. T., Prasad, V., Yang, P. T., Wu, J. F., David Ho, T. H., Charng, Y. Y., et al. (2003). Expression of arabidopsis cbf1 regulated by an aba/stress inducible promoter in transgenic tomato confers stress tolerance without affecting yield. Plant, Cell \& Environment, 26(7), 1181.

Martin, G. M., Austad, S. N., \& Johnson, T. E. (1996). Genetic analysis of ageing: Role of oxidative damage and environmental stresses. Nature Genetics, 13(1), 25-34.

Mittler, R., Vanderauwera, S., Gollery, M., \& Van Breusegem, F. (2004). Reactive oxygen gene network of plants. Trends In Plant Science, 9(10), 490-498.

Munne-Bosch, S., \& Alegre, L. (2002). Plant aging increases oxidative stress in chloroplasts. Planta, 214(4), 608-615.

Orr, W. C., \& Sohal, R. S. (1994). Extension of life-span by overexpression of superoxide-dismutase and catalase in drosophila-melanogaster. Science, 263(5150), 1128-1130.

Porra, R. J., Thompson, W. A., \& Kriedemann, P. E. (1989). Determination of accurate extinction coefficients and simultaneous equations for assaying chlorophylls a and $\mathrm{b}$ extracted with four different solvents: Verification of the concentration of chlorophyll standards by atomic absorption spectroscopy. Biochimica et biophysica acta, 975(3), 384.

Prochazkova, D., Sairam, R. K., Srivastava, G. C., \& Singh, D. V. (2001). Oxidative stress and antioxidant activity as the basis of senescence in maize leaves. Plant Science, 161(4), 765-771.

Sambrook, J., Fritsh, E. F., \& Maniatis, T. (1992). Molecular cloning: A laboratory manual. Cold Spring Harbor, NY: Cold Spring Harbor Laboratory.

Schopfer, P., Plachy, C., \& Frahry, G. (2001). Release of reactive oxygen intermediates (superoxide radicals, hydrogen peroxide, and hydroxyl radicals) and peroxidase in germinating radish seeds controlled by light, gibberellin, and abscisic acid. Plant Physiol., 125(4), 1591-1602.

Sharabi-Schwager, M., Lers, A., Samach, A., Guy, C. L., \& Porat, R. (2010). Overexpression of the cbf2 transcriptional activator in arabidopsis delays leaf senescence and extends plant longevity. Journal of Experimental Botany, 61(1), 261-273.

Shinozaki, K., \& Yamaguchi-Shinozaki, K. (2000). Molecular responses to dehydration and low temperature: Differences and cross-talk between two stress signaling pathways. Current Opinion In Plant Biology, 3(3), 217-223.

Shinwari, Z. K., Nakashima, K., Miura, S., Kasuga, M., Seki, M., Yamaguchi-Shinozaki, K., et al. (1998). An arabidopsis gene family encoding dre/crt binding proteins involved in low-temperature-responsive gene expression. Biochemical and Biophysical Research Communications, 250(1), 161-170.

Thomashow, M. F. (1999). Plant cold acclimation: Freezing tolerance genes and regulatory mechanisms. Annual review of plant physiology and plant molecular biology, 50, 571-599.

Thomashow, M. F. (2001). So what's new in the field of plant cold acclimation? Lots! Plant physiology, 125, 89-93.

Weigal, D., \& Glazebrook, J. (2002). Arabidopsis: A labratory manual. Cold Spring Harbor, New York: cold spring harbor labratory press.

Woo, H. R., Kim, J. H., Nam, H. G., \& Lim, P. O. (2004). The delayed leaf senescence mutants of arabidopsis, ore1, ore3, and ore9 are tolerant to oxidative stress. Plant And Cell Physiology, 45(7), 923-932.

Zimmermann, P., \& Zentgraf, U. (2005). The correlation between oxidative stress and leaf senescence during plant development. Cellular \& Molecular Biology Letters, 10(3), 515-534. 
Table 1. Expression levels of reactive oxygen species (ROS) scavenging network genes in mature leaves of wild-type (WS ecotype) and $C B F 2$-overexpressing plants.

\begin{tabular}{|c|c|c|c|}
\hline Enzyme and Reaction & Locus & Name & $\begin{array}{c}\text { Fold change } \\
(C B F 2-0 x / \text { WS })\end{array}$ \\
\hline Superoxide Dismutase (SOD) & At4g25100.3 & FeSOD (FSD1) & -1.05 \\
\hline \multirow[t]{7}{*}{$\mathrm{O}_{2}^{-}+\mathrm{O}_{2}^{-}+2 \mathrm{H}^{+} \rightarrow \mathrm{H}_{2} \mathrm{O}_{2}+\mathrm{O}_{2}$} & At5g51100.1 & FeSOD (FSD2) & -1.04 \\
\hline & At5g23310.1 & FeSOD (FSD3) & -1.03 \\
\hline & At1g08830.1 & $\mathrm{Cu} / \mathrm{ZnSOD}(\mathrm{CSD} 1)$ & 1.24 \\
\hline & At2g28190.1 & $\mathrm{Cu} / \mathrm{ZnSOD}(\mathrm{CSD} 2)$ & 1.33 \\
\hline & At5g 18100.1 & $\mathrm{Cu} / \mathrm{ZnSOD}$ (CSD3) & 1.34 \\
\hline & At3g10920.1 & MnSOD (MSD1) & 1.08 \\
\hline & At3g56350.1 & MnSOD-like & nd \\
\hline Ascorbate Peroxidase (APX) & At1g07890.1 & APX1 & -1.18 \\
\hline \multirow{8}{*}{$2 \mathrm{Asc}+\mathrm{H}_{2} \mathrm{O}_{2} \rightarrow 2 \mathrm{MDA}+2 \mathrm{H}_{2} \mathrm{O}$} & At3g09640.1 & APX2 & nd \\
\hline & At4g35000.1 & APX3 & -1.00 \\
\hline & At4g09010.1 & APX4 & 1.29 \\
\hline & At4g35970.1 & APX5 & nd \\
\hline & At4g32320.1 & APX6 & -1.01 \\
\hline & Atlg33660.1 & APX7 & nd \\
\hline & At4g08390.2 & stromal-APX & 1.21 \\
\hline & At1g77490.1 & thylakoid-APX & 1.07 \\
\hline Monodehydroascorbate Reductase (MDAR) & At1g63940.4 & MDAR1 & 1.38 \\
\hline \multirow{4}{*}{$\mathrm{MDA}+\mathrm{NAD}(\mathrm{P}) \mathrm{H}+\mathrm{H}^{+} \rightarrow \mathrm{Asc}+\mathrm{NAD}(\mathrm{P})^{-}$} & At3g09940.1 & MDAR2 & nd \\
\hline & At3g27820.1 & MDAR3 & 1.07 \\
\hline & At3g52880.1 & MDAR4 & 1.21 \\
\hline & At5g03630.1 & MDAR5 & -1.83 \\
\hline Dehydroascorbate Reductase (DHAR) & At5g16710.1 & DHAR1 & 1.01 \\
\hline \multirow{4}{*}{$\mathrm{DHA}+2 \mathrm{GSH} \rightarrow \mathrm{Asc}+\mathrm{GSSG}$} & At5g36270.1 & DHAR2 & nd \\
\hline & Atlg75270.1 & DHAR3 & -1.12 \\
\hline & At1g19550.1 & DHAR4 & nd \\
\hline & Atlg19570.1 & DHAR5 & 1.77 \\
\hline Glutathione Reductase (GR) & At3g24170.1 & GR1 & 1.09 \\
\hline $\mathrm{GSSG}+\mathrm{NAD}(\mathrm{P}) \mathrm{H} \rightarrow 2 \mathrm{GSH}+\mathrm{NAD}(\mathrm{P})^{-}$ & At3g54660.1 & GR2 & 1.05 \\
\hline Catalase (Cat) & At1g20630.1 & Cat1 & 1.29 \\
\hline \multirow{2}{*}{$2 \mathrm{H}_{2} \mathrm{O}_{2} \rightarrow 2 \mathrm{H}_{2} \mathrm{O}+\mathrm{O}_{2}$} & At4g35090.1 & Cat2 & -1.10 \\
\hline & At1g20620.1 & Cat3 & -1.86 \\
\hline Glutathione Peroxidase (GPX) & At2g25080.1 & GPX1 & -1.10 \\
\hline \multirow[t]{7}{*}{$\mathrm{H}_{2} \mathrm{O}_{2}+2 \mathrm{GSH} \rightarrow 2 \mathrm{H}_{2} \mathrm{O}+\mathrm{GSSG}$} & At2g31570.1 & GPX2 & -1.15 \\
\hline & At2g43350.1 & GPX3 & -1.07 \\
\hline & At2g48150.1 & GPX4 & nd \\
\hline & At3g63080.1 & GPX5 & -1.08 \\
\hline & At4g31870.1 & GPX7 & 1.11 \\
\hline & Atlg63460.1 & GPX8 & -1.17 \\
\hline & At4g11600.1 & Phospholipid GPX6 & 1.33 \\
\hline Ferritin & At5g01600.1 & Ferritin 1 & 1.02 \\
\hline \multirow{3}{*}{$\mathrm{Fe}+\mathrm{P} \rightarrow \mathrm{P}-\mathrm{Fe}$} & At3g56090.1 & Ferritin 2 & -1.08 \\
\hline & At2g40300.1 & Ferritin 3 & 1.22 \\
\hline & At3g11050.1 & Ferritin 4 & nd \\
\hline Peroxiredoxin (PrxR) & Atlg48130.1 & 1- cys PrxR & nd \\
\hline \multirow[t]{10}{*}{$2 \mathrm{P}-\mathrm{SH}+\mathrm{H}_{2} \mathrm{O}_{2} \rightarrow$ P-S-S-P $+2 \mathrm{H}_{2} \mathrm{O}$} & At3g11630.1 & 2-cys PrxR A & 1.07 \\
\hline & At5g06290.1 & 2-cys PrxR B & 1.13069 \\
\hline & At3g06050.1 & 2-cys $\operatorname{PrxR} F$ & 1.15 \\
\hline & At3g26060.1 & PrxR Q & 1.08 \\
\hline & Atlg65990.1 & Type 2 PrxR A & nd \\
\hline & At1g65980.1 & Type 2 PrxR B & -1.11 \\
\hline & At1g65970.1 & Type 2 PrxR C & nd \\
\hline & Atlg60740.1 & Type 2 PrxR D & nd \\
\hline & At3g52960.1 & Type 2 PrxR E & 1.09 \\
\hline & At3g03405.1 & Type 2 PrxR-related & nd \\
\hline
\end{tabular}


The list of Arabidopsis ROS-scavenging genes was taken from Mittler et al. (2004). For gene expression analysis, RNA was isolated from leaves numbers. 5 and 6 of wild-type and CBF2-overexpressing plants 40 days after sowing. Expression values are from gene profiling experiment using the Affymetrix ATH1 genome array. nd, not detected (expression level below background).

Table 2. Expression levels of oxidative stress-responsive transcription factor genes in mature leaves of wild-type (WS ecotype) and $C B F 2$-overexpressing plants.

\begin{tabular}{|c|c|c|}
\hline Locus & Name & $\begin{array}{c}\text { Fold change } \\
(C B F 2-0 x / \text { WS })\end{array}$ \\
\hline At5g 13080 & AtWRKY75 & nd \\
\hline Atlg62300 & AtWRKY6 & $4.01^{\S}$ \\
\hline At1g10585 & bHLH transcription factor & 2.77 \\
\hline At3g04070 & NAM transcription factor & $3.23^{¥}$ \\
\hline At2g38340 & DREB transcription factor & nd \\
\hline At $2 \mathrm{~g} 38250$ & GT-1-like transcription factor & nd \\
\hline At $2 \mathrm{~g} 30250$ & AtWRKY25 & $4.56^{\S}$ \\
\hline At1g52890 & NAM transcription factor & $4.37^{\S}$ \\
\hline At2g43000 & NAM transcription factor & nd \\
\hline At3g15500 & AtNAC3 & nd \\
\hline At5g63790 & NAM transcription factor & $6.27^{£}$ \\
\hline At2g26150 & AtHSFA2 & nd \\
\hline At5g05410 & DREB2A & 2.86 \\
\hline At4g23810 & AtWRKY53 & $4.82^{\S}$ \\
\hline At1g43160 & ERF/AP2 transcription factor & 2.28 \\
\hline At4g17230 & scarecrow-like transcription factor & $4.48^{\S}$ \\
\hline At4g17490 & AtERF6 & nd \\
\hline At4g17500 & AtERF1 & nd \\
\hline At5g04340 & $\mathrm{C}_{2} \mathrm{H}_{2}$ zinc finger & $5.18^{£}$ \\
\hline At5g59820 & ZAT12 & $6.09^{£}$ \\
\hline At5g47220 & AtERF2 & nd \\
\hline At3g50260 & DREB transcription factor & $3.27^{¥}$ \\
\hline At4g27410 & NAM transcription factor & $7.66^{£}$ \\
\hline At4g18880 & AtHsfA4A & $6.03^{\mathfrak{f}}$ \\
\hline At1g25560 & AP2 transcription factor & $5.54^{£}$ \\
\hline At1g18570 & AtMYB51 & nd \\
\hline At3g23250 & AtMYB15 & nd \\
\hline At1g77450 & NAM transcription factor & $5.88^{\mathfrak{E}}$ \\
\hline At1g27730 & ZAT10 & $6.43^{£}$ \\
\hline At1g80840 & AtWRKY40 & $4.17^{\S}$ \\
\hline At2g40140 & CCCH-type zinc finger & $5.10^{\mathfrak{f}}$ \\
\hline At $2 \mathrm{~g} 38470$ & AtWRKY33 & $6.13^{\mathfrak{f}}$ \\
\hline
\end{tabular}

The list of transcription factors commonly up-regulated (at least fivefold) in Arabidopsis by oxidative stress is

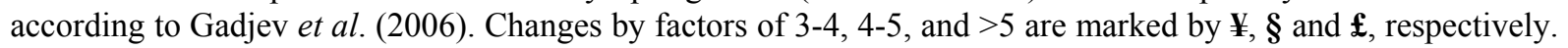
For gene expression analysis, RNA was isolated from leaves numbers 5 and 6 of wild-type and CBF2-overexpressing plants 40 days after sowing. Expression values are from gene profiling experiment with the Affymetrix ATH1 genome array. nd, not detected (expression level below background). 


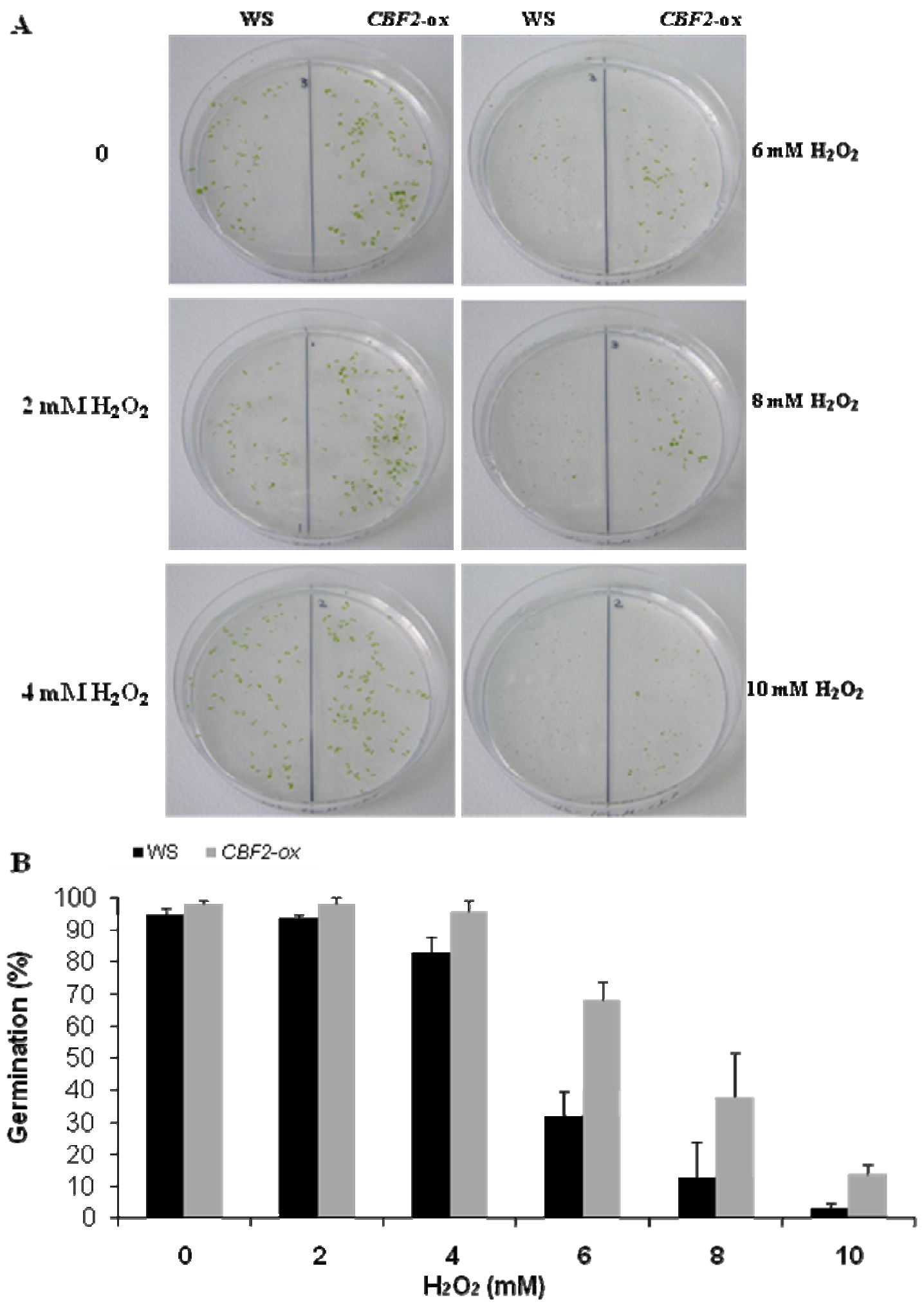

Figure 1. Effects of hydrogen peroxide $\left(\mathrm{H}_{2} \mathrm{O}_{2}\right)$ on seed germination of wild-type and $C B F 2$-overexpressing plants. Seeds were grown in Petri dishes in MS-agar in the presence of several different concentration $(0-10 \mathrm{mM})$ of $\mathrm{H}_{2} \mathrm{O}_{2}$ A, Photographs taken after 7 days of growth at $22^{\circ} \mathrm{C}$. B, Seed germination rates following growth in the presence of various concentrations of $\mathrm{H}_{2} \mathrm{O}_{2}$. Data are means \pm S.E. of two different experiments, each including three replications. 
A

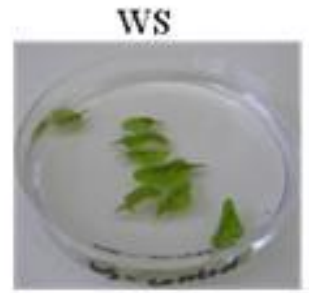

CBF2-ox

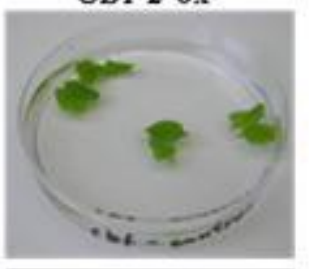

$2.5 \mathrm{mM} \mathrm{H}_{2} \mathrm{O}_{2}$
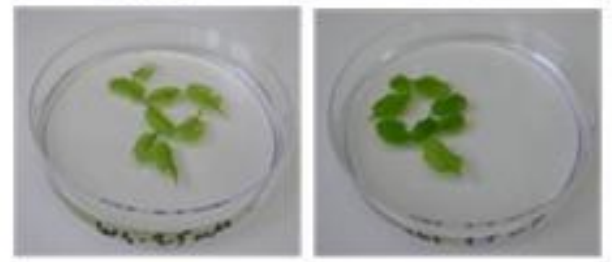

$5 \mathrm{mM} \mathrm{H}_{2} \mathrm{O}_{2}$
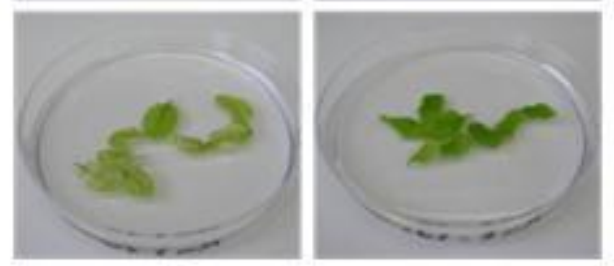

$7.5 \mathrm{mM} \mathrm{H}_{2} \mathrm{O}_{2}$
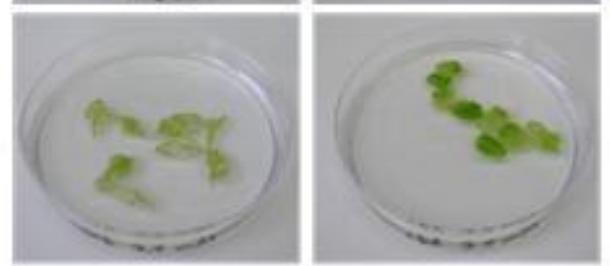

$10 \mathrm{mM} \mathrm{H}_{2} \mathrm{O}_{2}$
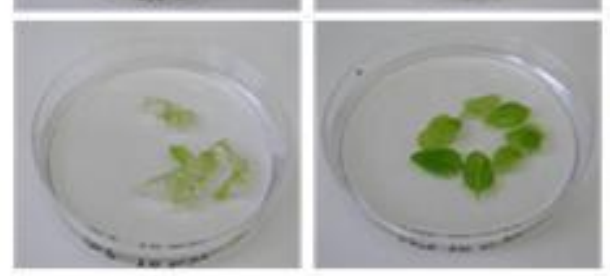

B

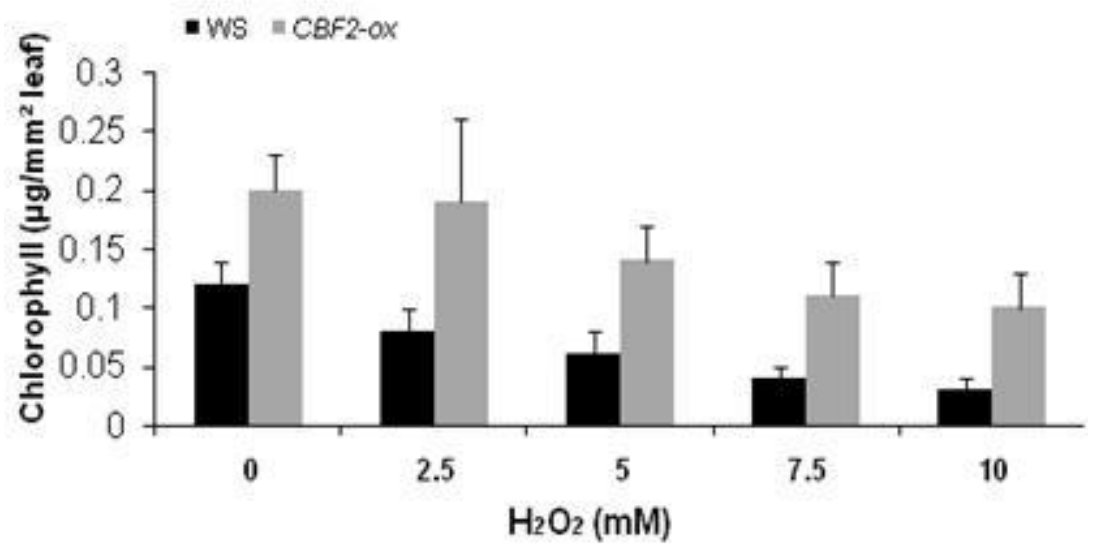

Figure 2. Effects of hydrogen peroxide $\left(\mathrm{H}_{2} \mathrm{O}_{2}\right)$ on yellowing of detached leaves of wild-type and CBF2-overexpressing plants. A, Photographs of detached leaves after $72 \mathrm{~h}$ of incubation in 0-10 $\mathrm{mM} \mathrm{H}_{2} \mathrm{O}_{2}$. B, Chlorophyll contents of detached leaves after incubation in 0-10 $\mathrm{mM} \mathrm{H}_{2} \mathrm{O}_{2}$. Data are means of three different experiments, each including four replications. 

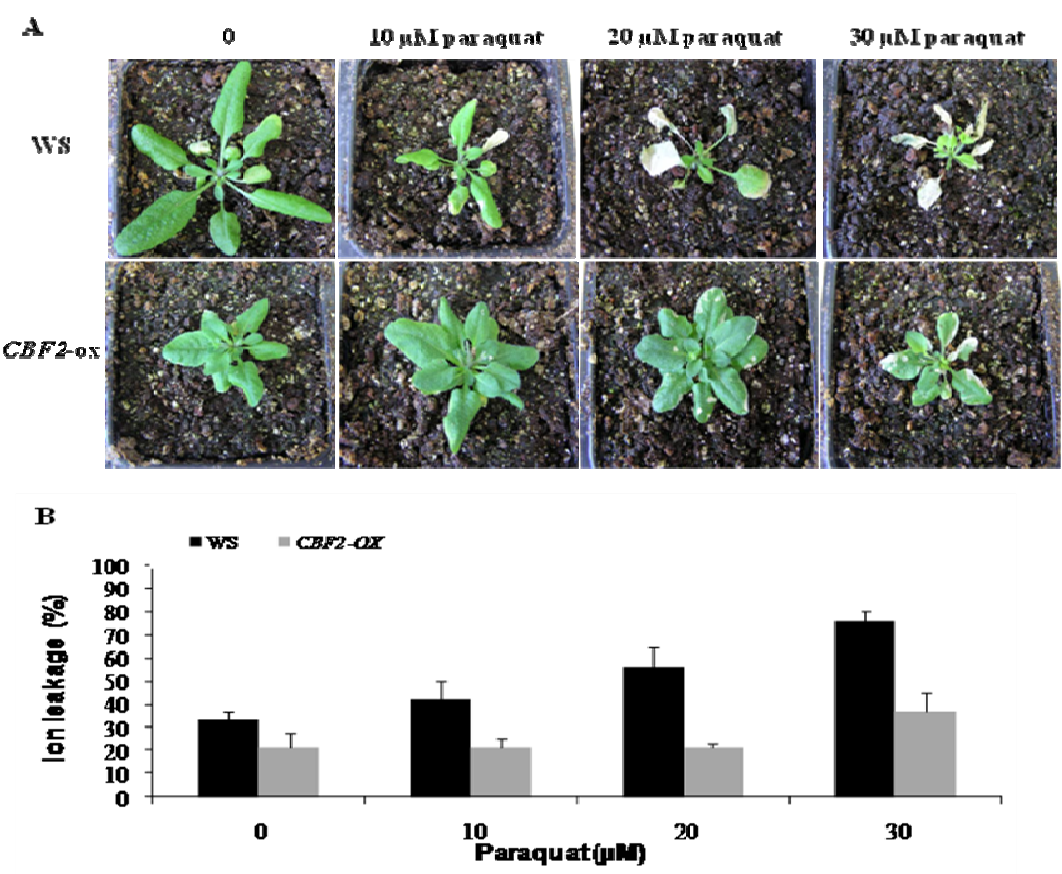

Figure 3. Effects of paraquat sprays on wilting and necrosis and of wild-type and $C B F 2$-overexpressing plants. A, Photographs taken 7 days after spraying the plants with $10-30 \mu \mathrm{M}$ paraquat. $\mathrm{B}$, Ion leakage rates after spraying the plants with 10-30 $\mu \mathrm{M}$ paraquat. Data are means of three different experiments, each including four replications.

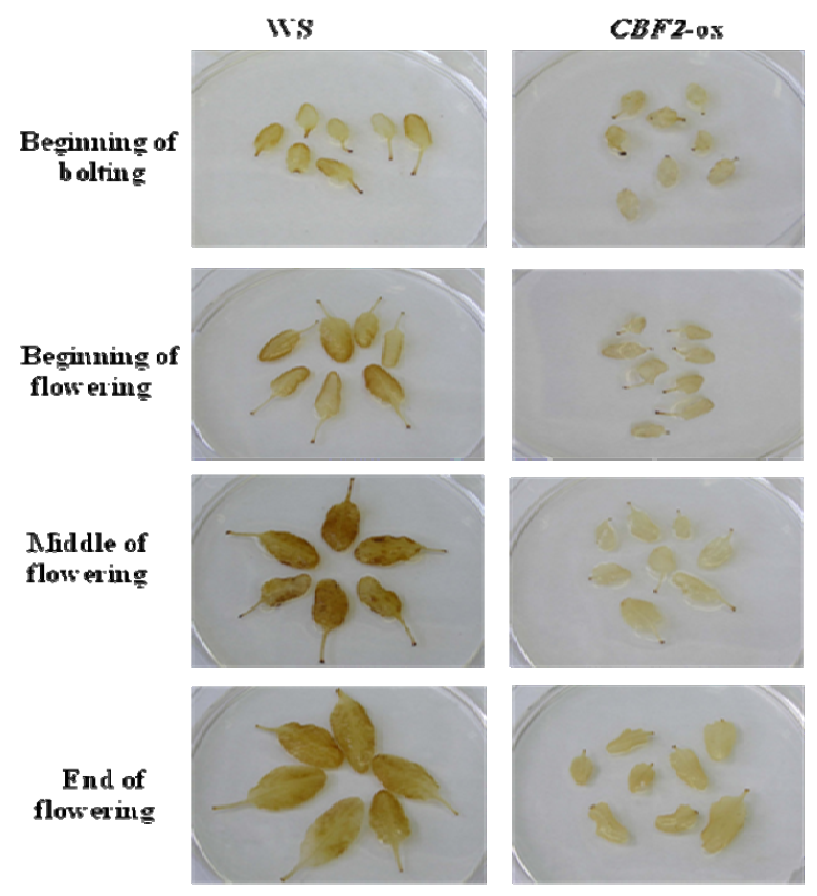

Figure 4. Evaluation of hydrogen peroxide $\left(\mathrm{H}_{2} \mathrm{O}_{2}\right)$ contents and accumulation in detached leaves of wild-type and $C B F 2$-overexpressing plants following 3,3'-diaminobenzidine (DAB) staining. Leaves in positions 5 and 6 were harvested from rosettes at various stages of plant development, including beginning of bolting, beginning of flowering, middle of flowering, and end of flowering. 


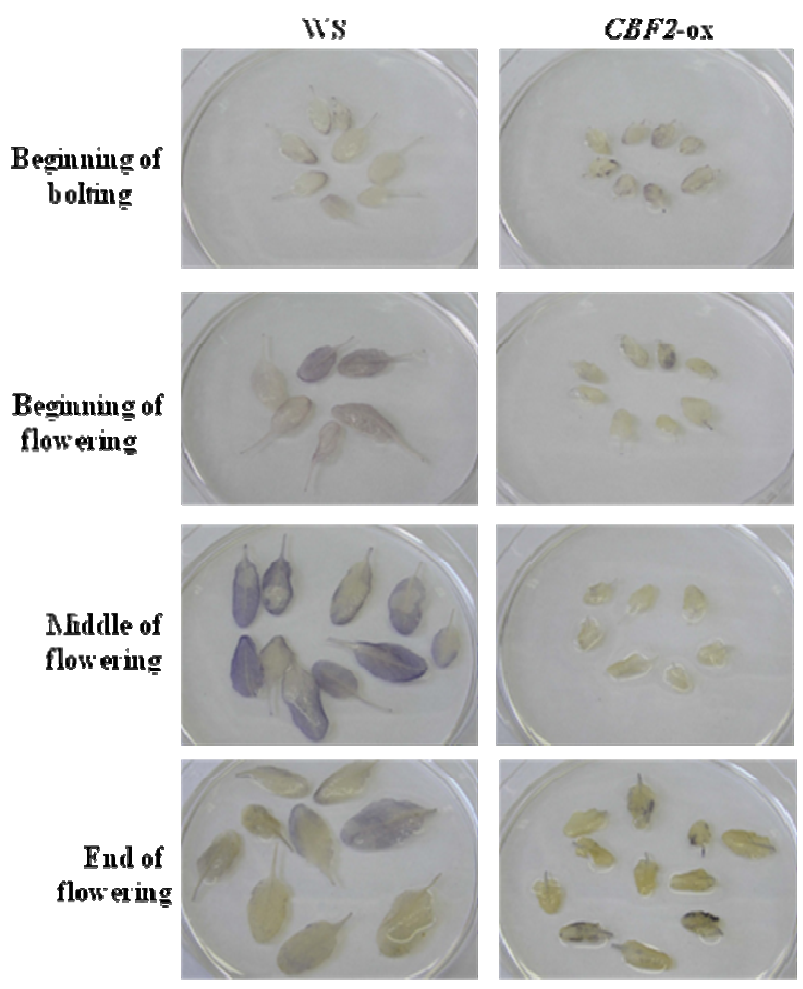

Figure 5. Evaluation of superoxide radical $\left(\mathrm{O}_{2}^{-}\right)$content and accumulation in detached leaves of wild-type and $C B F 2$-overexpressing plants following nitroblue tetrazolium (NBT) staining. Leaves in positions 5 and 6 were harvested from rosettes at various stages of plant development, including beginning of bolting, beginning of flowering, middle of flowering, and end of flowering.

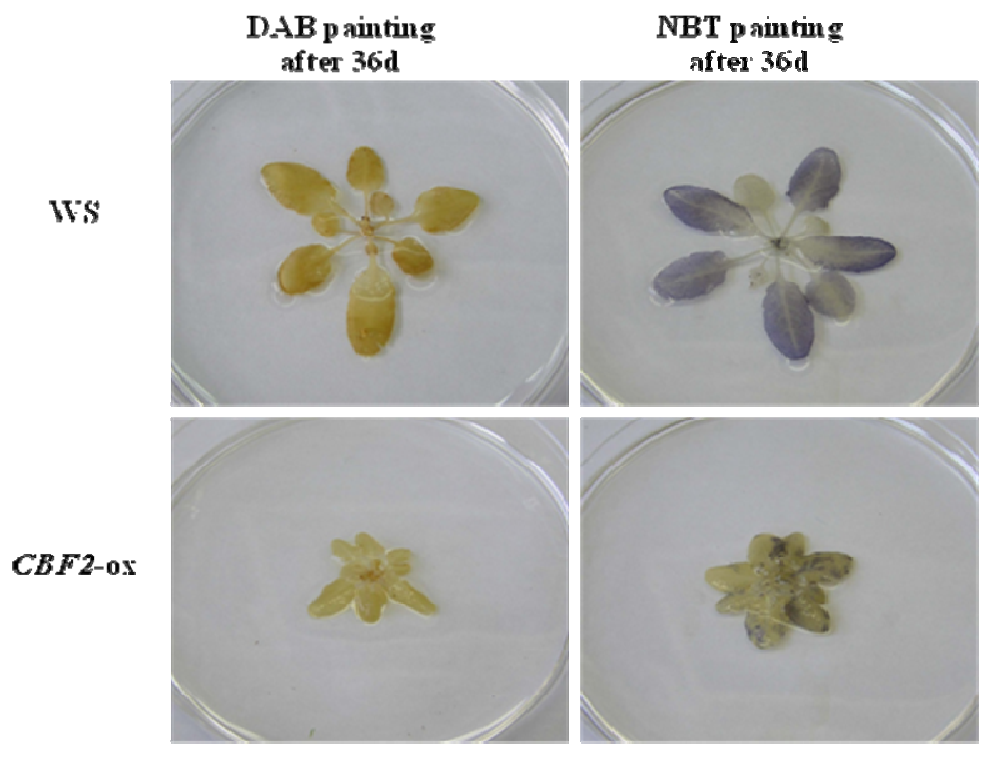

Figure 6. Evaluation of hydrogen peroxide $\left(\mathrm{H}_{2} \mathrm{O}_{2}\right)$ and superoxide radical $\left(\mathrm{O}_{2}{ }^{-}\right)$contents in 36-day-old rosettes of wild-type and $C B F 2$-overexpressing plants following 3,3'-diaminobenzidine (DAB) and nitroblue tetrazolium (NBT) staining. 